\title{
THE NEW SOCIAL REALITY AND SOCIO-PSYCHOLOGICAL TRANSFORMATIONS OF VALUES
}

Alaverdyan N. A. (Yerevan State University, Yerevan, Armenia) nalaverdyan@ysu.am

乙tinluјugưuน uर्u. 01.11.2021

9pmpunuर्umध шर्जu. 19.12.2021

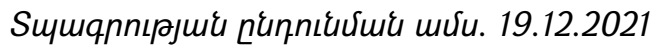

\begin{abstract}
At present, when the world is in transformation, a fresh interpretation of social-cultural function of values in construction and regulation of social life, social-cultural principles of coexistence, transferring of life-experience and formation of national identity have acquired a new theoretical and practical significance. Social life on the one hand is characterized by stable systems of values, norms, traditions and ideas that regulate relations, which enable the society to maintain its qualitative specificities, and on the other hand, it is characterized by continuous change and renewal. Social systems exist thanks to new sociocultural values, which provide the existence of the society and its development. The difficult process of combining old and new realities creates a precondition for the formation of a dichotomous worldview and dual social positions. During various historical periods, social systems survive because thanks to certain mechanisms they are supplemented with new sociocultural values. Modern society becomes more and more pluralistic and alternative and creates such moral-psychological atmosphere, when a person does not only feel cultural inferiority, but also becomes more adaptable to new attitudes and lifestyles. Old, tested values and norms regulating peoples thoughts and behavior clash with new, unfamiliar values. In this process on the one hand the conservativeness ensures stability within the society, and on the other, modernity adopts new values and aims at mobility and innovation. Under such conditions of radical transformations values fulfill the important function of overcoming socialcultural crises, adaptation to new conditions, reduction of struggle between the old and the new. From this point of view, values is not only stable and reliable basis for society, but also for its renewal and modernization.
\end{abstract}

Keywords: sociocultural values, unpredictability, uncertainty, modernization, consumer values, dichotomous worldview, transformation.

DOI: https://doi.org/10.46991/SBMP/2022.5.1.003

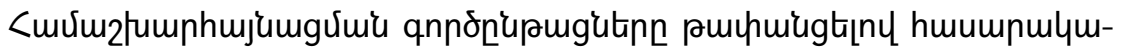

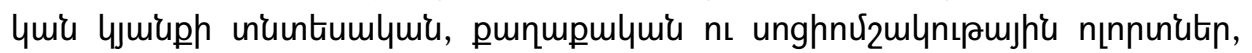

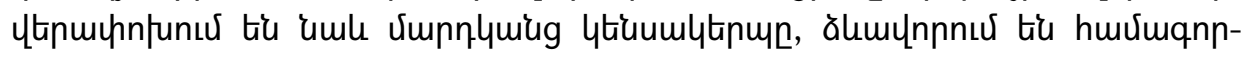




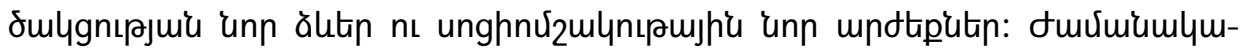

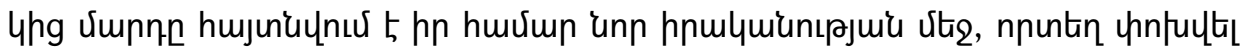

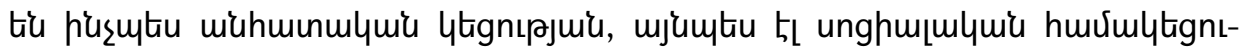

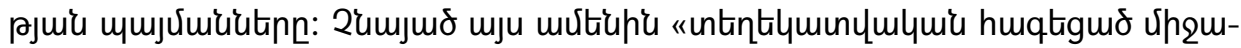

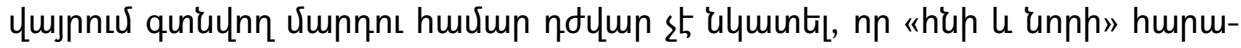

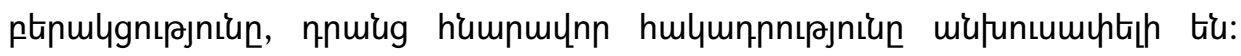

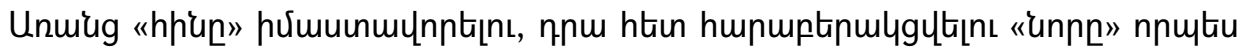

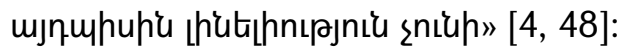

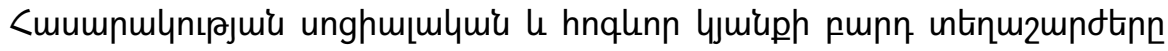

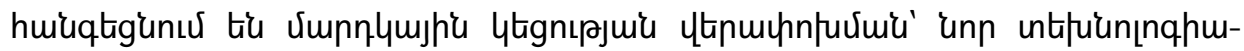

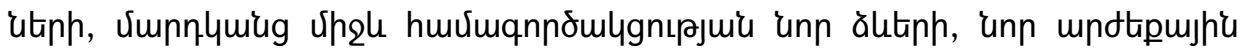

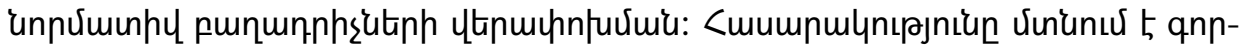

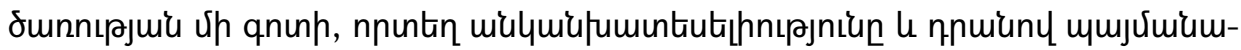

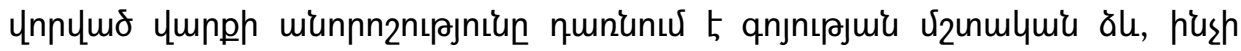

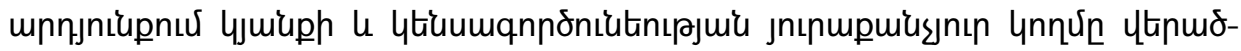

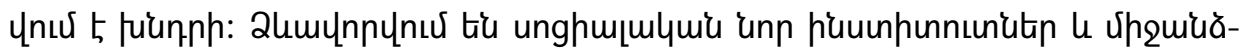

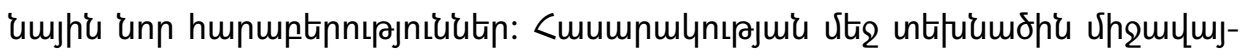

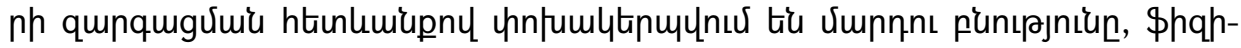

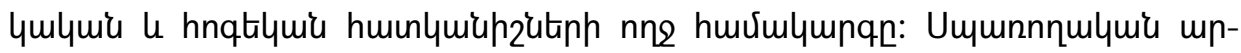

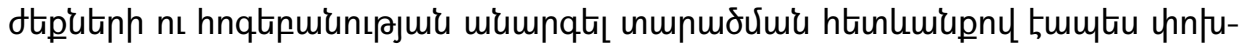

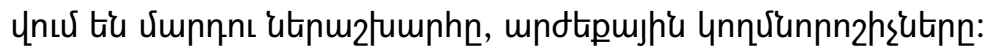

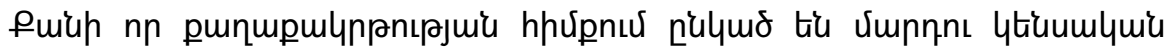

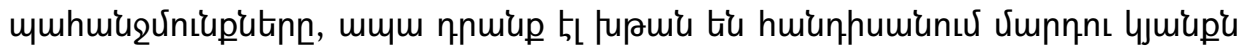

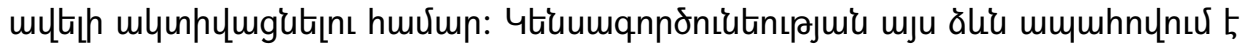

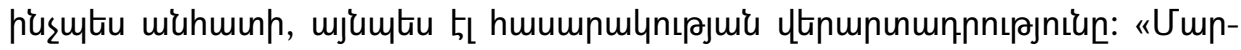

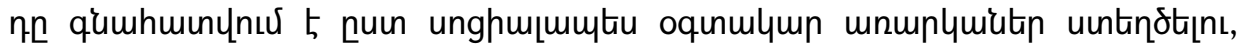

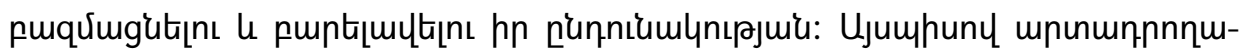

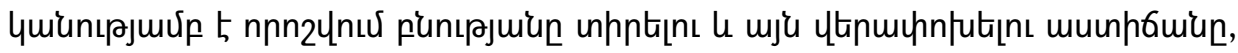

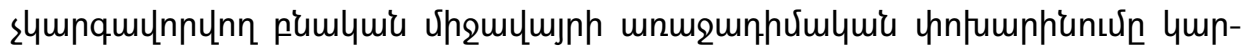

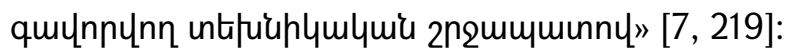

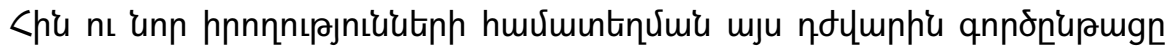

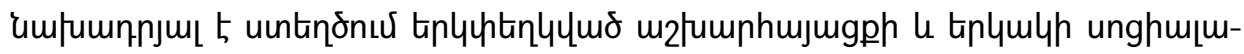

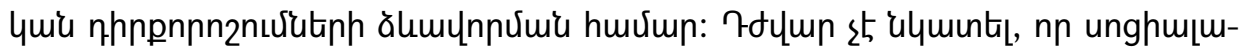

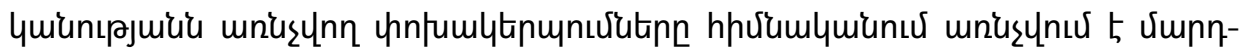

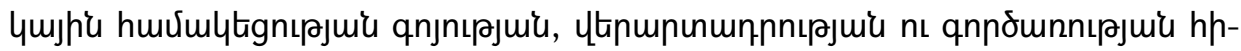

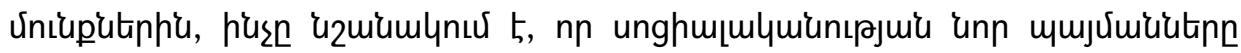

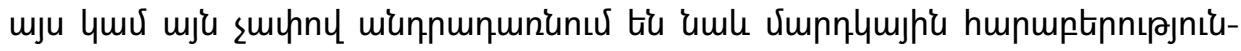

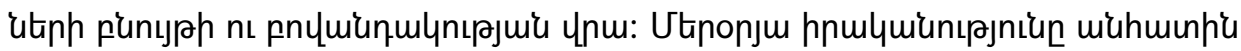

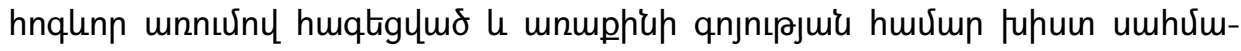

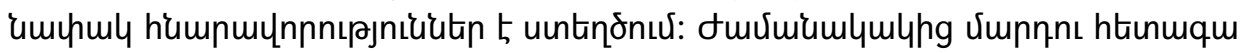




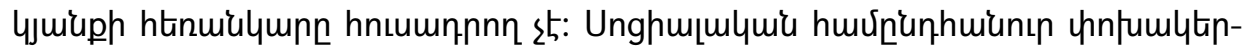

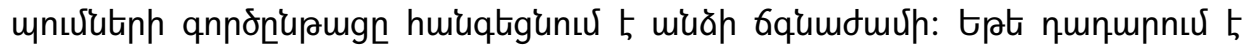

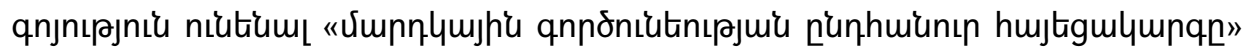

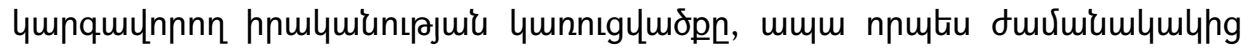

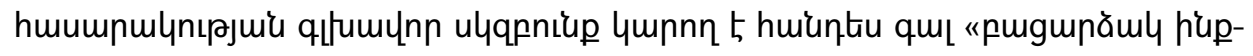

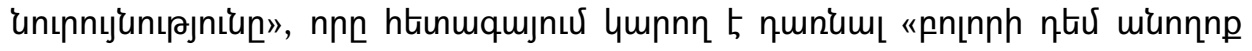

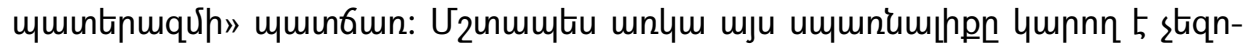

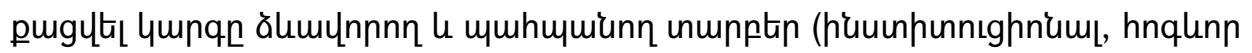

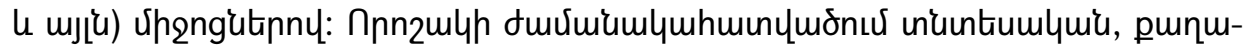

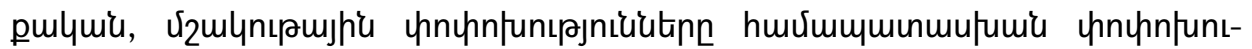

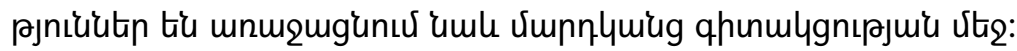

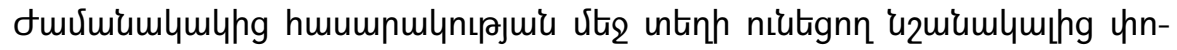

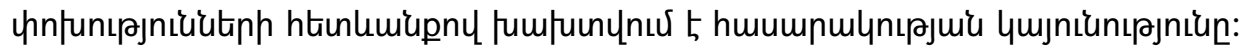

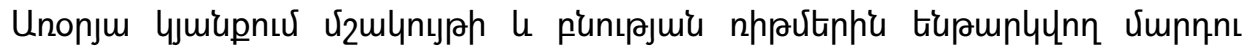

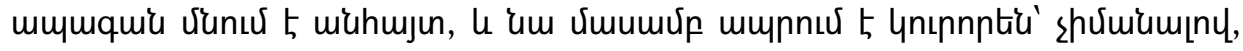

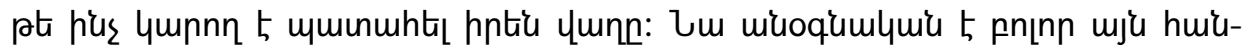

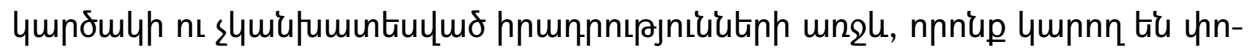

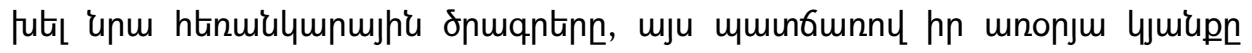

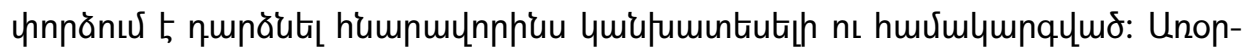

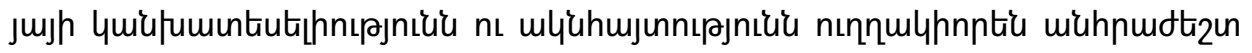

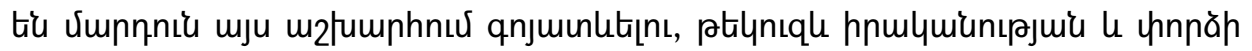

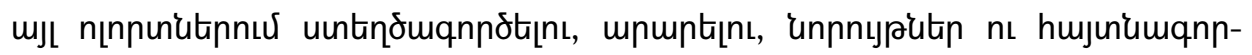

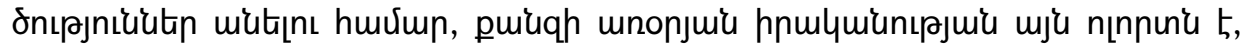

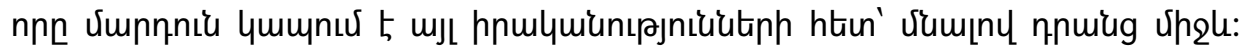

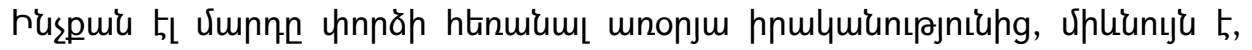

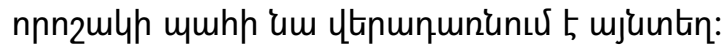

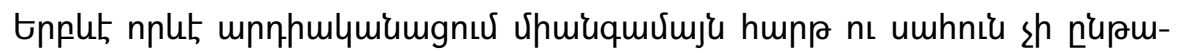

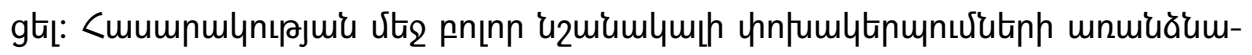

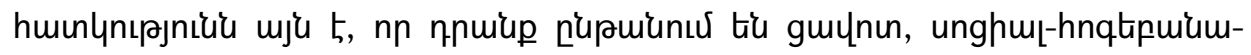

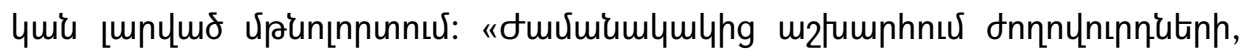

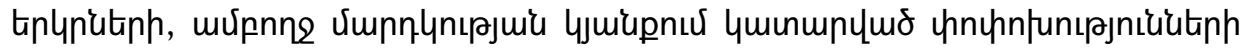

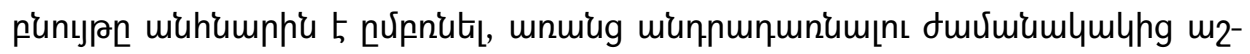

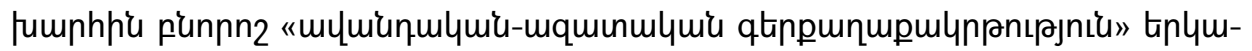

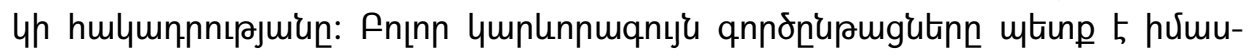

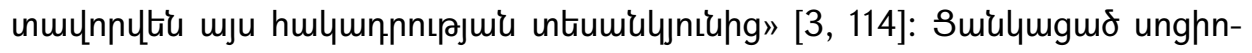

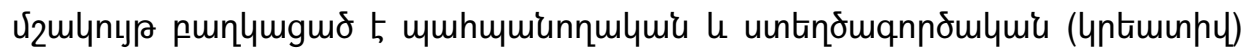

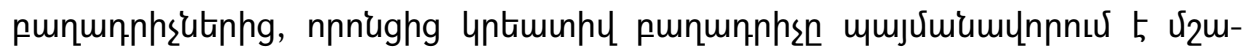

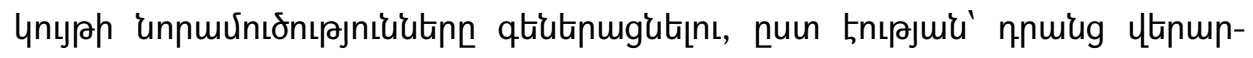

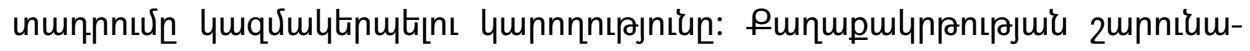

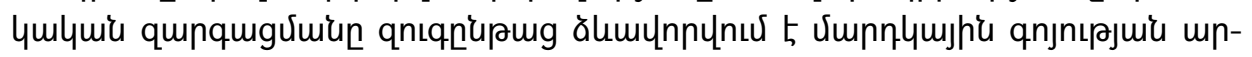




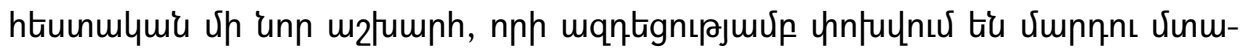

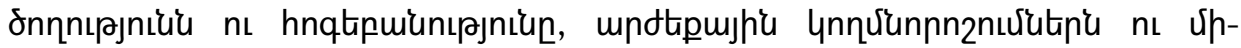

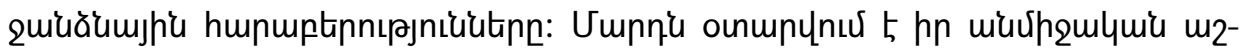

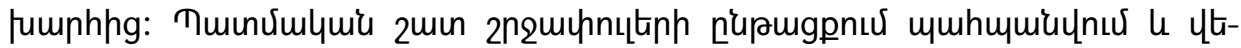

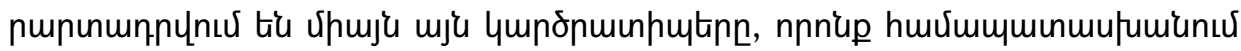

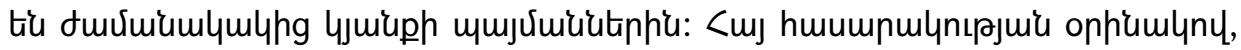

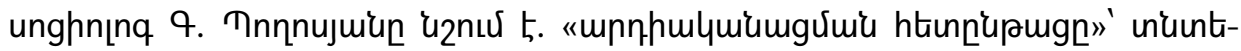

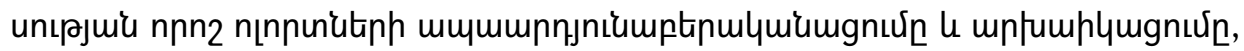

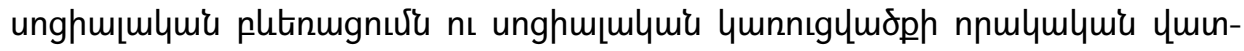

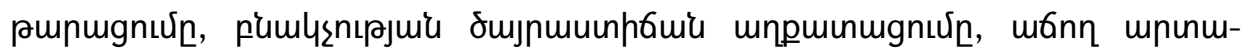

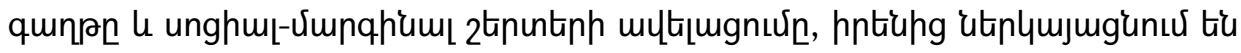

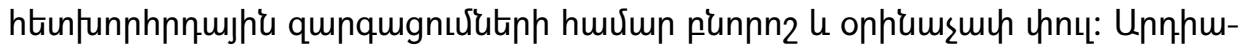

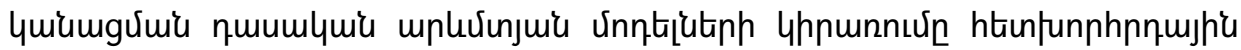

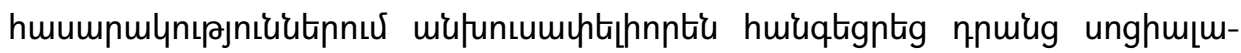

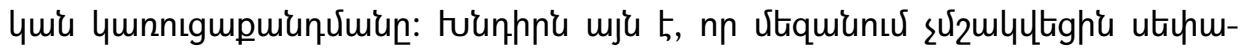

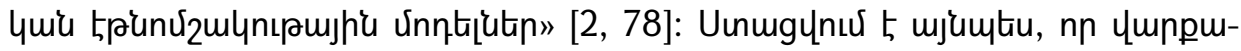

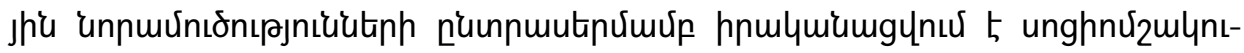

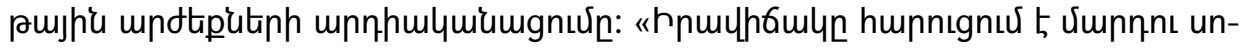

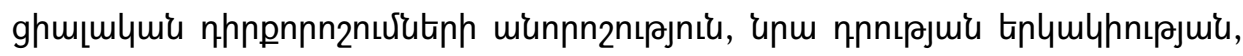

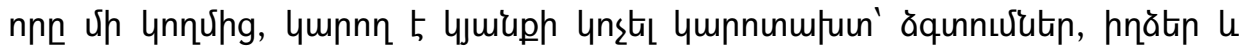

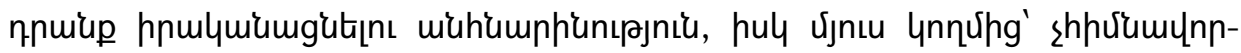

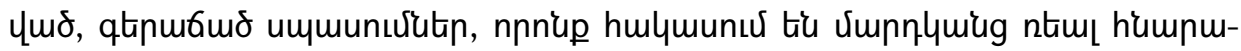

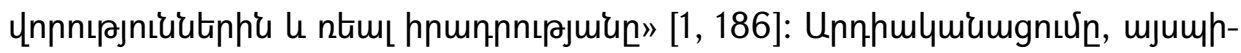

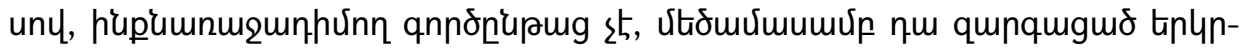

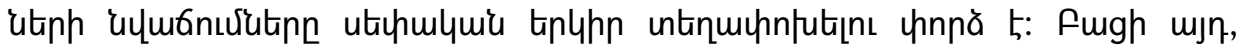

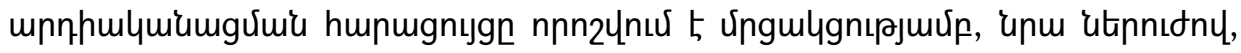

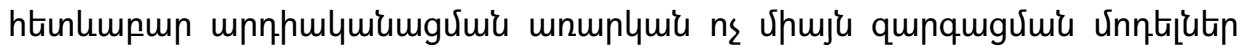

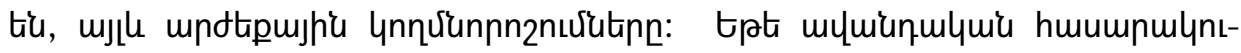

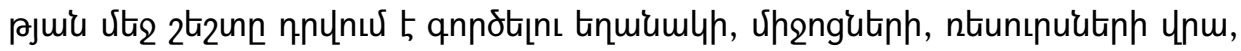

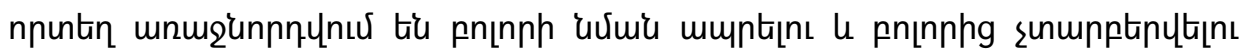

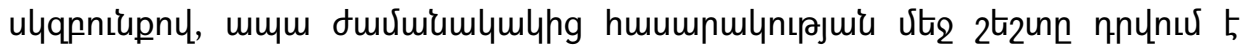

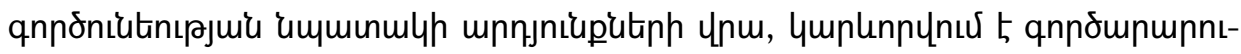

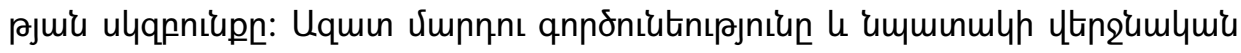

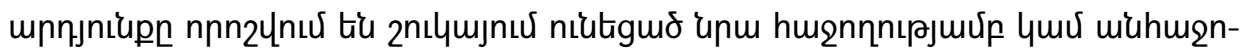

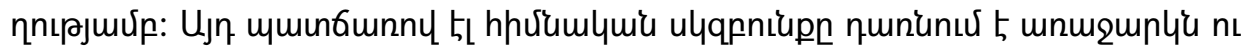

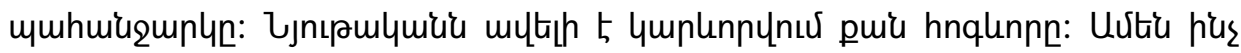

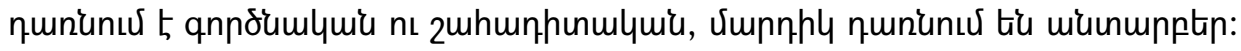

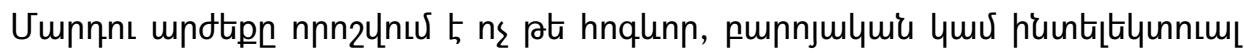

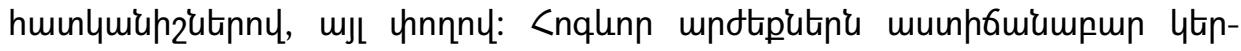

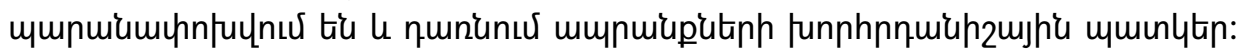




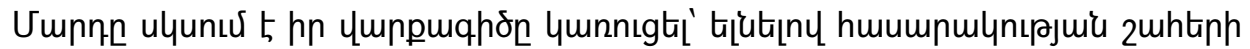

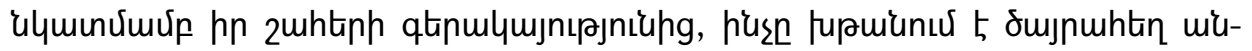
huinmumz

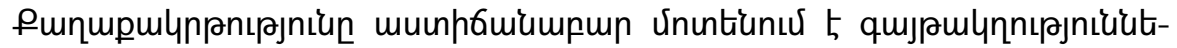

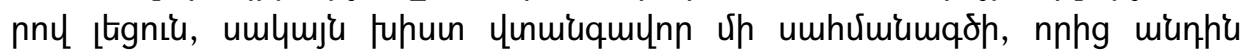

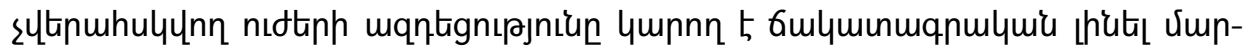

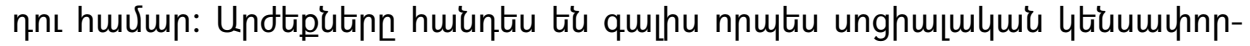

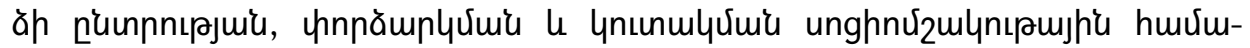

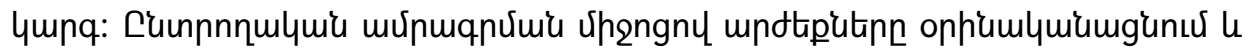

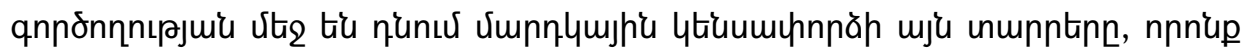

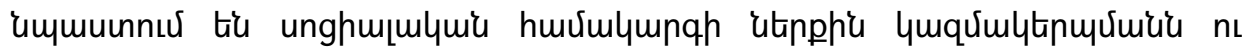

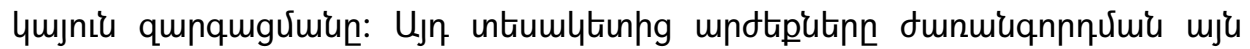

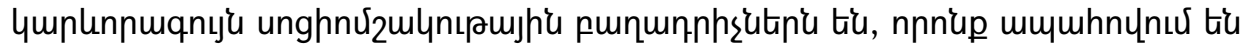

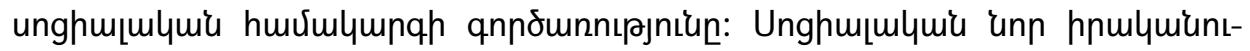

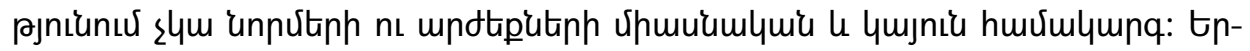

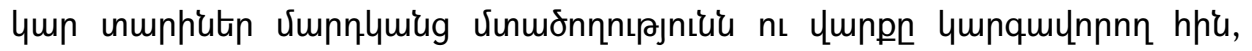

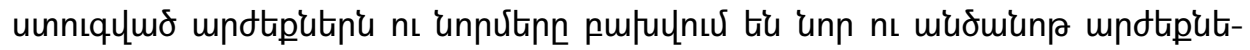

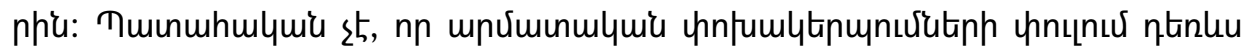

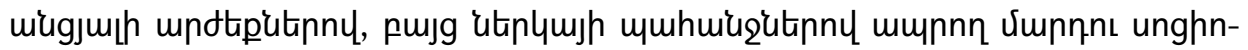

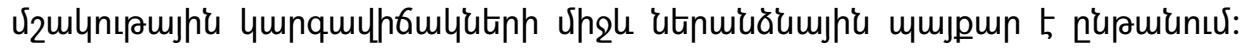

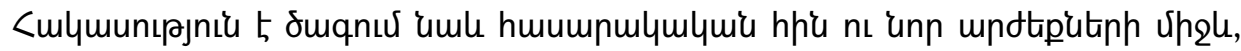

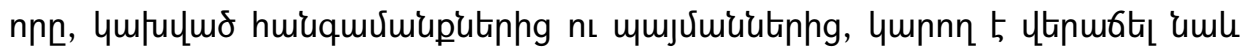

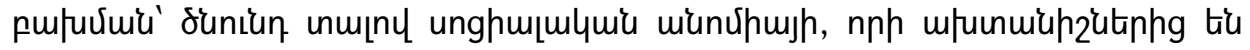

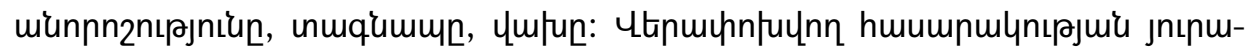

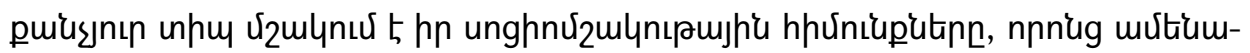

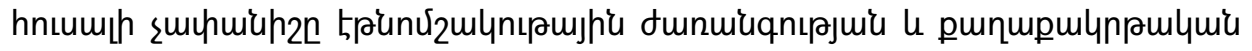

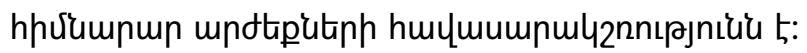

\section{9pulquiunıpjnıน}

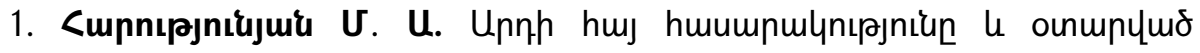

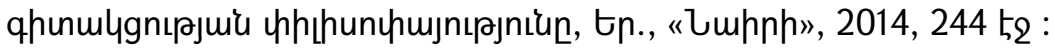

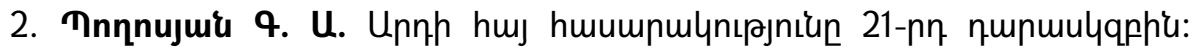
tp., "Lniumpug", 2006, 52 354:

3. Гавров С. Социокультурная традиция и модернизация российского общества. М., МГУКИ, 2002, с.146.

4. Захарченко М. В. Христианство: духовная традиция в истории и культуре.СПб., 2001, с. 68.

5. Ирхин Ю.В. К вопросу о кросскультурных исследования: ВостокЗапад//Социологические исследования. 2005, №2, с.131-135. 
6. Кастельс М. Информационная эпоха: экономика, общество и культура, //http://polbu.ru/kastels_informepoch/

7. Маркузе Г. Эрос и цивилизация. Одномерный человек. Исследование идеологии развитого индустриального общества, М., "АСТ», 2003, с. 319.

8. Рене Г. Царство количества и знамения времени. М., 2011, с. 158.

9. Хабермас Ю. Концепции модерна. Ретроспектива двух традиций. Политические работы. М., «Праксис», 1995, с. 368.

10.Швыров В.С. Рациональность как ценность культуры.Традиция и современность. М., 2003, с.176.

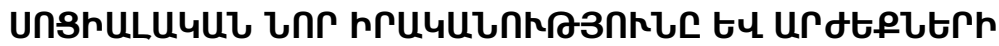

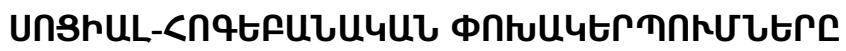

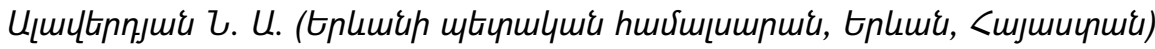

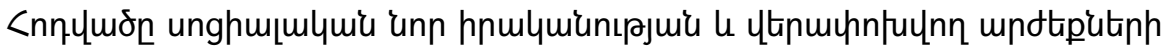

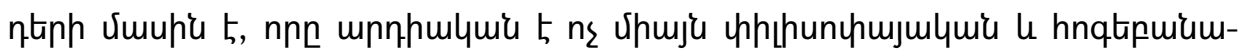

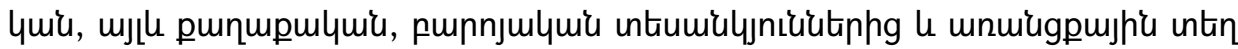

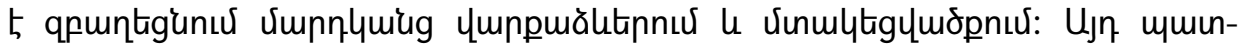

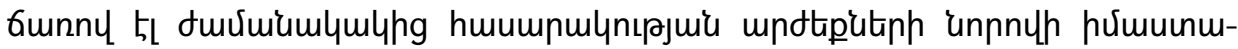

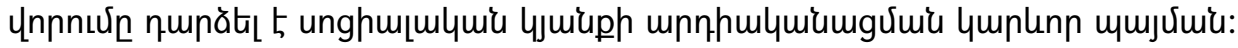

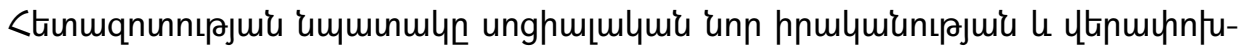

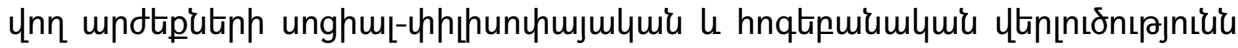

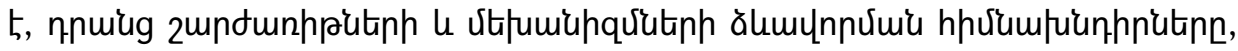

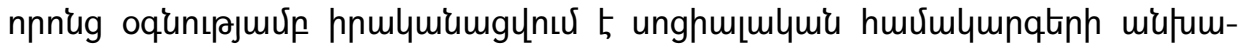

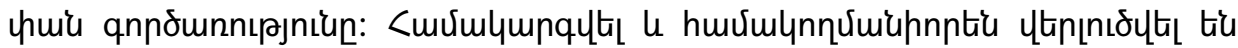

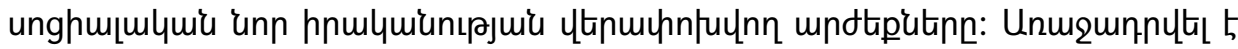

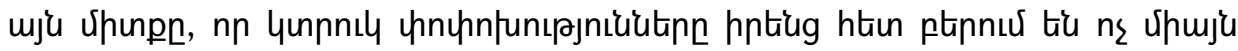

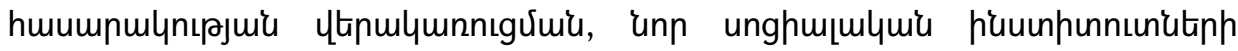

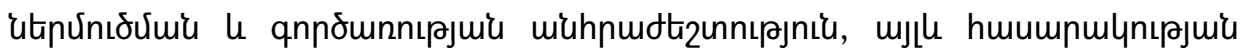

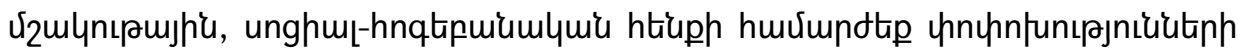

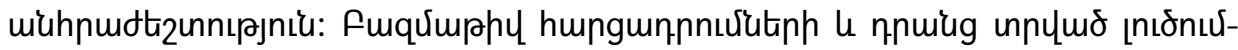

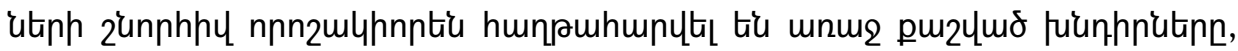

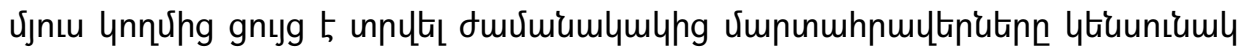

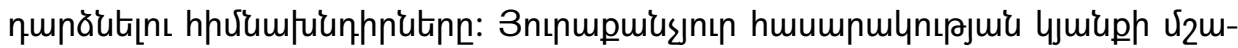

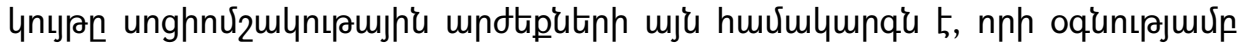

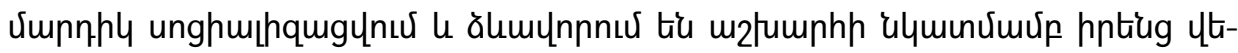

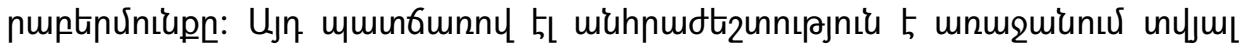

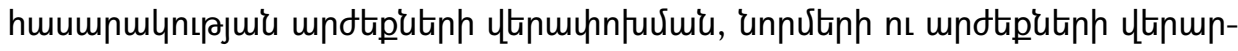

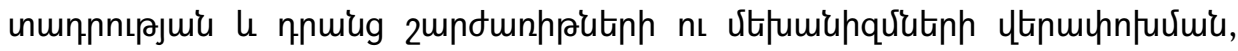




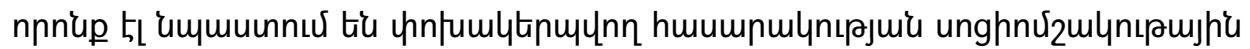

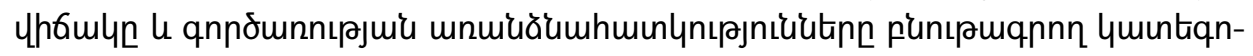

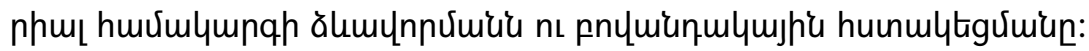

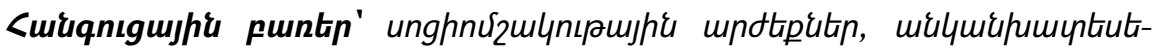

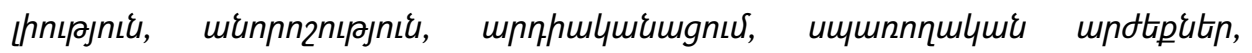

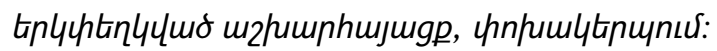

\section{НОВАЯ СОЦИАЛЬНАЯ РЕАЛЬНОСТЬ И СОЦИАЛЬНО- ПСИХОЛОГИЧЕСКАЯ ТРАНСФОРМАЦИЯ ЦЕННОСТЕЙ}

Алавердян Н. А. (Ереванский государственный университет, Ереван, Армения)

В настоящее время, мир трансформируется, новая интерпретация социокультурной функции ценностей в построении и регулировании общественной жизни, социокультурные принципы сосуществования, передача жизненного опыта и формирование национальной идентичности приобрели новое теоретическое обоснование и практическое значение. Социальная жизнь, с одной стороны, характеризуется стабильными системами ценностей, норм, традиций и идей, каторые регулируют отношения, каторые позволяют обществу сохранять свои качественные особенности, а с другой стороны, для нее характерны постоянные изменения и обновления. Социальные системы существуют благодаря новым социокультурным ценностям, которые обеспечивают существование общества и его развитие. Сложный процесс сомещения старых и новых реалий создает предпосылки для формирования дихотомического мировоззрения и двойных социальных позиций. В разные исторические периоды социальные системы выживают, потому что благодаря определенным механизмом они дополняются новыми социокультурными ценностями. Современное общество становится все более пируалистическим и альтернативным и создает такую морально-психологическую атмосферу, когда человек не только ощущает культурную неполноценность, но и становится более приспособленным к новым взглядом и образу жизни. Старые, проверенные цанности и нормы, регулирующие мысли и поведение людей, вступают в противоречие с новым, незнакомыми ценностями. В этом процессе, с одной стороны, консервативность обеспечивает стабильность в обществе, а с другой стороны современность принимает новые ценности и стремится к мобильности и инновациям. В таких условиях радикальных преобразований ценности выполняют важную функцию преодоления социокультурных кризисов, адаптации к новым условиям, уменшения борьбы меж- 
ду старым и новым. С этой точки зрения ценности-это не только стабильная и надежная основа для общества, но и для его обновления и модернизации.

Ключевые слова: Сочиокультурные ченности, непредскзуемость, неопределенность, модернизация, потребительские ченности, дихотомическое мировоззрение, трансорормация. 